\title{
The French Wilms' tumour study: no clear evidence for cancer prone families
}

\author{
C Moutou, J Hochez, A Chompret, M-F Tournade, C Le Bihan, J-M Zucker, \\ J Lemerle, C Bonaïti-Pellié
}

\begin{abstract}
Wilms' tumour of the kidney is known to occur in Beckwith-Wiedemann syndrome. It has also been described in four cancer prone families displaying $\mathrm{Li}$ Fraumeni syndrome but it is not usually considered to be part of this syndrome. In order to detect particular familial cancer aggregations associated with this tumour, we studied the cancer incidence and mortality among relatives of the 501 Wilms' tumour patients in the French Wilms' Tumour Study. We found no familial association with breast cancer or soft tissue sarcomas which are the most common cancers in the Li-Fraumeni syndrome. However, we found two significant familial associations of Wilms' tumour with bone cancers on the one hand and with brain tumours on the other hand. These associations could reflect a small proportion of families segregating for some susceptibility gene. This should then be confirmed at the molecular level.
\end{abstract}

( $\mathcal{F}$ Med Genet 1994;31:429-434)

Wilms' tumour (WT) of the kidney (or nephroblastoma) is an embryonal tumour affecting young children, usually before the age of $10 .{ }^{1}$ Since there are several similar epidemiological features in retinoblastoma and Wilms' tumour (existence of both unilateral and bilateral cases with earlier age at onset for bilateral cases, familial occurrence), Wilms' tumour was thought for a long time to arise from the same mechanism as retinoblastoma which is a paradigm of childhood cancers. ${ }^{2}$ Wilms' tumour was thus thought to occur after two mutations at homologous loci of a tumour suppressor gene resulting in loss of normal gene function. ${ }^{34}$ By this hypothesis, most unilateral cases are sporadic resulting from two somatic events whereas all bilateral and rare unilateral cases are the result of one inherited

This study was undertaken in collaboration with members of the SFOP (Sociéte Française d'Oncologie Pédiatrique): C Bachelot (Grenoble), M Brunat-Mentigny (Lyon), F Dusol (Lille), D Frappaz (Saint-Etienne), M Munzer (Reims), H Roché (Toulouse), D Sommelet-Olive (Nancy), D Steschenko (Nancy), P Tron (Rouen) (or new germline) altered gene followed by a somatic event. In fact, WT carcinogenesis seems to be more complex than previously thought. Molecular studies have shown that at least three loci are probably involved in WT carcinogenesis ${ }^{5}$ : WT1 at $11 \mathrm{p} 13$ in patients displaying WAGR syndrome (Wilms' tumour, Aniridia, Genitourinary abnormalities, and mental Retardation), WT2 at $11 \mathrm{p} 15.5$ in patients with Beckwith-Wiedemann syndrome (multiorgan developmental abnormalities and predisposition to cancers including WT), and WT3, still unmapped and involved in a substantial amount of familial WT since linkage analyses of three families segregating for WT excluded tight linkage with $11 \mathrm{p} 13$ and 11 p15.5. ${ }^{6-8}$ Furthermore, all bilateral cases being hereditary has been questioned. ${ }^{2910}$ Non-random loss of maternal alleles at $11 \mathrm{p} 15$ in sporadic $W^{11-13}$ and an excess of transmitting females in $\mathrm{BWS}^{14-16}$ suggest genomic imprinting in WT. Our recent findings using genetic epidemiological methods on the data of the French Wilms' tumour study are in agreement with this hypothesis. ${ }^{10}$ The human $\mathrm{H} 19$ gene, located at $11 \mathrm{p} 15$, monoallelically expressed, ${ }^{17}$ and whose active allele is lost in some WT, ${ }^{18}$ is a good candidate for a WT2 susceptibility gene.

Familial occurrence of WT is rare and the frequency of WT in relatives of patients is low. In the French Wilms' tumour study, frequencies of WT were estimated to be less than $0.4 \%$ in sibs, $0.06 \%$ in first cousins, and $0.04 \%$ in uncles and aunts. ${ }^{19}$

Wilms' tumour is well known to occur in Beckwith-Wiedemann syndrome or in the WAGR syndrome. It has also exceptionally been described in cancer prone families and especially in Li-Fraumeni syndrome (LFS), described as the familial aggregation of sarcomas, breast cancers, leukaemias, brain tumours, and adrenocortical carcinomas, usually occurring before the age of 45 . Wilms' tumour is not considered to be part of the LFS but this remains to be confirmed, especially since four LFS families were described with a case of Wilms' tumour. ${ }^{20-23}$

The purpose of this study is to search for a global excess of cancers among the relatives of Wilms' tumour patients and to detect particular familial cancer aggregations suggesting an inherited susceptibility. 


\section{Material}

Between 1982 and 1989, complete family histories and clinical data were collected for 501 children with Wilms' tumour from several departments of pediatric oncology in France: 337 from the Institut Gustave Roussy in Villejuif, 56 from the Institut Curie in Paris, and 108 from other centres in France. ${ }^{19}$ Respectively, four, three, and two patients were diagnosed as having WAGR, BWS, and Drash syndrome. Familial data were obtained either by direct interview with the parents, or by a self-questionnaire given to the parents and brought back at the next visit. Family information consisted of sex, date of birth, eventual occurrence of tumours or anomalies, and eventual date and cause of death among patients' relatives including sibs, parents, grandparents, uncles, aunts, and first cousins.

\section{Methods}

Two different approaches were used to search for an excess of cancers among relatives of Wilms' tumour patients. On the one hand, we dealt with cancer mortality, and on the other with cancer incidence.

\section{CANCER MORTALITY}

Although cancer mortality is an indirect measure of the frequency of cancer, it uses good population data. French statistics for mortality ${ }^{24}{ }^{25}$ have effectively been registered since 1945 which allows birth cohort effects to be taken into account. However, we could not confirm causes of death mentioned by persons interviewed since death certificates are anonymous in France. Subjects who were known to have cancer but had died from another cause were counted as not cancer. The expected number of cancer deaths was calculated from French statistics for each class of relatives, for each sex, for each five year age group and each one year period from 1943 to 1990 . Two indicators were used to calculate expected values: (1) the Standardised Mortality Ratio (SMR) based on the number of cancer deaths in the general population: $S M R=\frac{d}{D E}$ where $d$ is the observed number of cancer deaths and $D_{E}$ the expected number of cancer deaths based on applying the cancer mortality rates to the number of people in each of the classes; (2) the Standardised Proportional Mortality Ratio (SPMR) based on the number of cancer deaths among dead persons in the general population: $S P M R=\frac{d}{D E P}$ where $D_{E P}$ is the expected number of cancer deaths based on applying proportional cancer mortality ratio in each of the classes.

Expected and observed values were compared by a classical $\chi^{2}$ test. When the expected number of cancer deaths was too small to perform a $\chi^{2}$ test, the exact probability was computed using binomial distribution.

Comparison of observed and expected values was first performed for cancers of all sites. Since breast cancer is frequent and is a major feature of LFS, we also studied mor- tality from breast cancer in our sample of relatives.

\section{CANCER INCIDENCE}

Cancer incidence is the exact measure of cancer frequency and requires knowledge of age at diagnosis which implies ascertainment of the diagnosis. Unfortunately, French incidence data ${ }^{26}$ are recent and birth cohort effect cannot be taken into account. Searching for familial cancer aggregation was performed treating each family separately. For one family $i$, the probability $P_{i}$ to have at least one affected relative before the age of 45 is:

$$
P_{i}=1-\sum_{j=1}^{k} 1-c_{j}
$$

where $\mathrm{k}$ is the number of relatives and $\mathrm{cr}_{j}$ the cumulative risk of subject $j$, according to age and sex, and given by French statistics ${ }^{26}$ The expected number of families with at least one affected relative before the age of 45 among $n$ families is:

$$
P=\sum_{i=1}^{n} P_{i}
$$

Observed and expected values were compared by a classical $\chi^{2}$ test. This test was performed using incidence data for all types of cancer and then for each cancer included in the Li-Fraumeni syndrome (that is, soft tissue sarcomas, breast cancer, bone cancer, brain tumours, and leukaemias). Adrenocortical carcinoma was not considered since it is too rare in the population as well as in the LFS.

\section{Results \\ MORTALITY}

Comparison between observed and expected numbers of cancer deaths applying the SPMR and the SMR is shown in tables 1 and 2 respectively. When using the SPMR, a significant excess is observed for grandfathers $(p<0.001)$ and for parents $(p=0.003)$. There is also an excess among fathers and aunts but this may not be significant given the number of tests performed. When using the SMR, there is a non-significant excess of cancer deaths in almost all categories of relatives. The validity of these tests will be discussed later.

\section{INCIDENCE}

The results of comparisons between observed and expected numbers of families with at least one relative diagnosed as having cancer before the age of 45 are shown in table 3 . When dealing with all types of cancer, there is no excess of such families. One can even note a deficit (39 observed families versus 78 expected). There is also no excess of breast cancers, soft tissue sarcomas, or leukaemias. Our analysis, however, concludes that there is a significant association between WT and either bone cancers $(p=0.028)$ or brain tumours $(p=0 \cdot 014)$. Pedigrees with relatives 
Table 1 Observed and expected number of cancer deaths with the SPMR methods

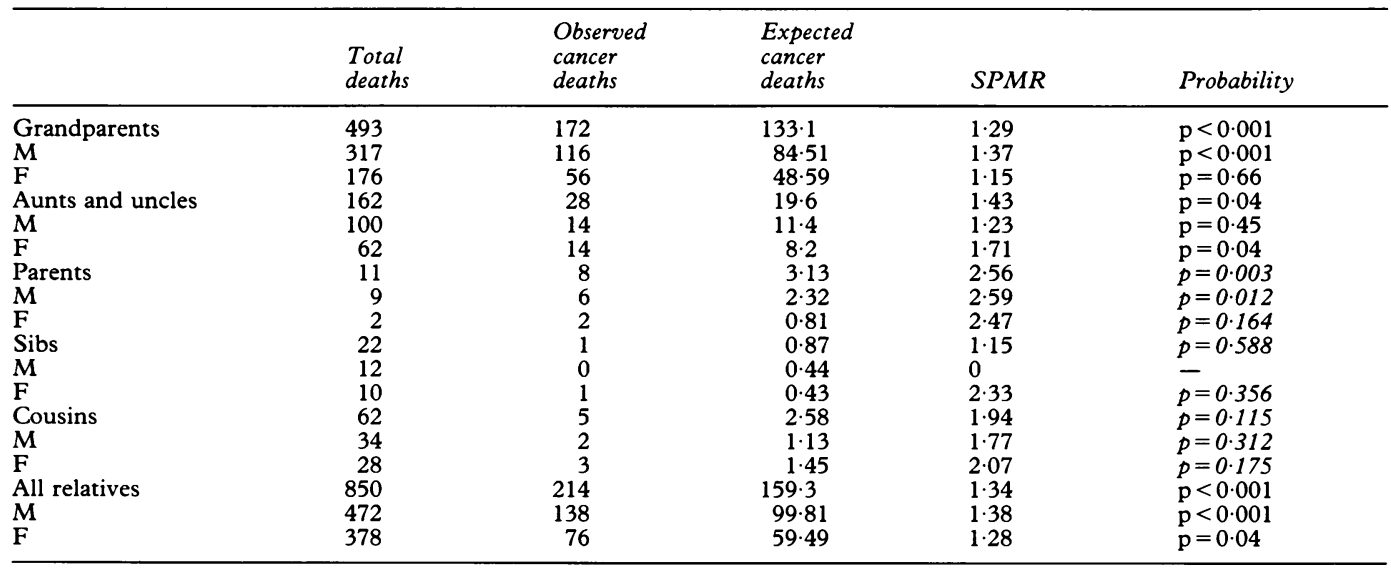

In italics: exact probability using binomial distribution.

Table 2 Observed and expected number of cancer deaths with the SMR methods

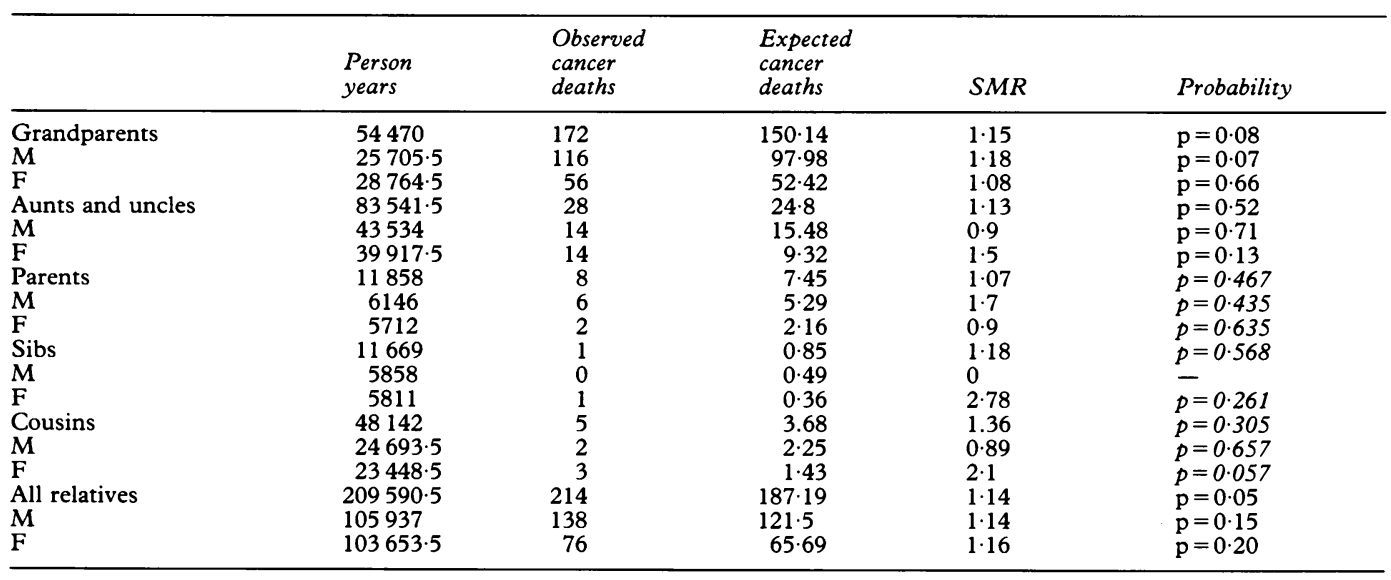

In italics: exact probability using binomial distribution.

affected by bone or brain tumours are shown in figs 1 and 2 respectively. There is no histological homogeneity among bone cancers (fig 1): one osteosarcoma (family 3), one Ewing's tumour (family 2), one ameloblastoma (family 5), and two unspecified bone tumours (families 1 and 4). There is only one affected relative in all the families except in family 2 where a case of bilateral WT has two cousins from the same sibship with Hodgkin's disease and Ewing's tumour respectively. M.Ioreover their mother and the proband's mother are twins. When dealing with families with at least one relative diagnosed as having a brain tumour (fig 2), it can be seen that only one family has more than two cancers (family 6): the proband's WT, one brain tumour in a first cousin, and two early onset breast cancers in aunts.

\section{Discussion}

There is no significant excess of cancer deaths among relatives of Wilms' tumour patients

Table 3 Observed and expected numbers of families with at least one relative diagnosed as having cancer before the age of 45

\begin{tabular}{lccl}
\hline & Observed & Expected & \\
\hline Breast & 3 & 3.75 & NS \\
Bone & 5 & 1.93 & $\mathrm{p}=0.028$ \\
Brain & 5 & 1.74 & $\mathrm{p}=0.014$ \\
STS & 1 & $2 \cdot 12$ & NS \\
Leukaemia & 8 & $9 \cdot 39$ & NS \\
All cancers & 39 & 78.25 & \\
\hline
\end{tabular}

except among grandfathers and parents, but this excess is only found by using the Standardised Proportional Mortality Ratio (SPMR). However, this estimator is often biased since it is based on the ratio between the number of cancer deaths and the total number of deaths. The denominator may be underestimated since non-cancer deaths may be unknown because of lack of follow up. SPMR can thus lead to an overestimation of cancer deaths. ${ }^{27}$ The Standardised Mortality Ratio (SMR), based on the whole set of at risk persons (alive and dead), is not affected by this bias and is a better indicator for cancer mortality. Note that the excess of cancer deaths previously shown in relatives of retinoblastoma patients ${ }^{28}$ and in a preliminary analysis of the first set of WT patients ${ }^{29}$ was found using the SPMR methods and may be because of an overestimation of cancer versus non-cancer deaths. There is no excess of breast cancer deaths which does not support the hypothesis that WT is part of the LFS.

Incidence analysis confirms part of the results obtained with mortality ratios but, even if there is no excess of cancer among the whole set of relatives, we found a significant familial association between Wilms' tumour and bone cancers on the one hand and brain tumours on the other hand. This association may be even stronger for two reasons. First, since our data on cancer occurrence only result from family interview, there could be a deficit of cancer 
432

Mouton, Hochez, Chompret, Tournade, Le Bihar, Bucker, Lemerle, Bonaiti-Pellié
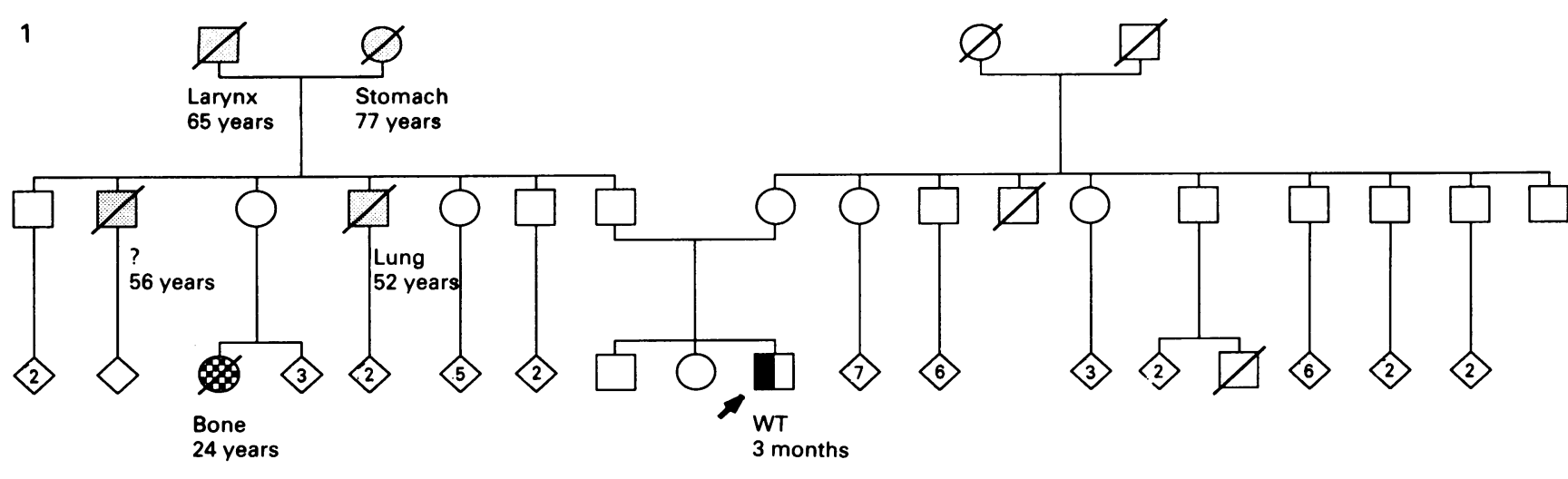

2

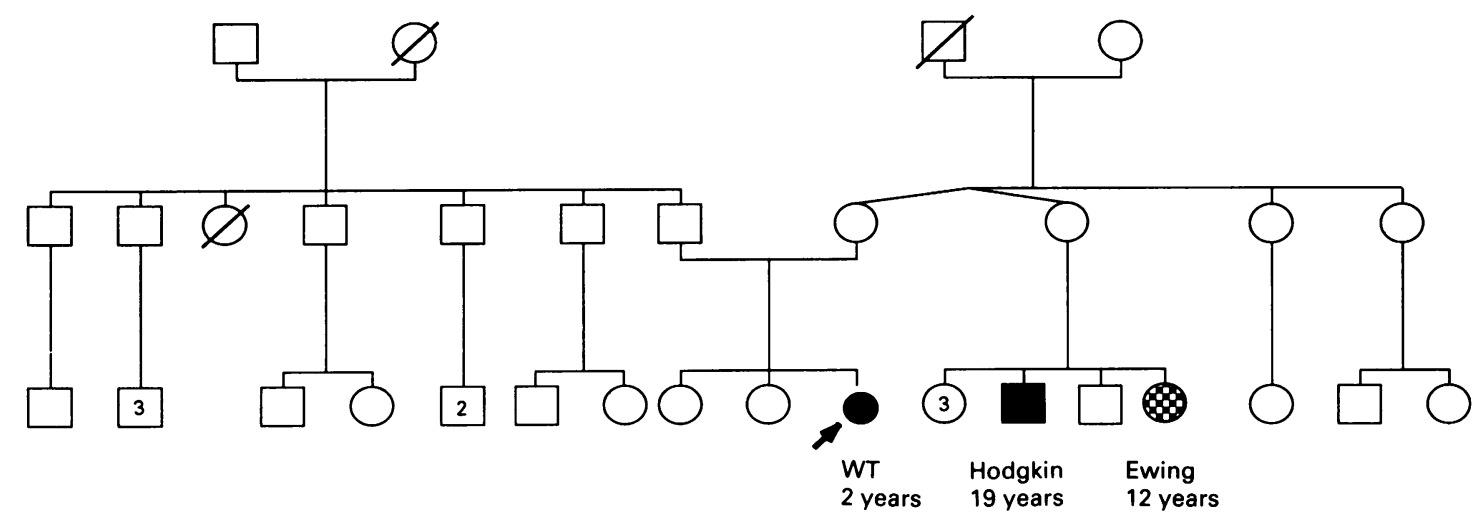

3

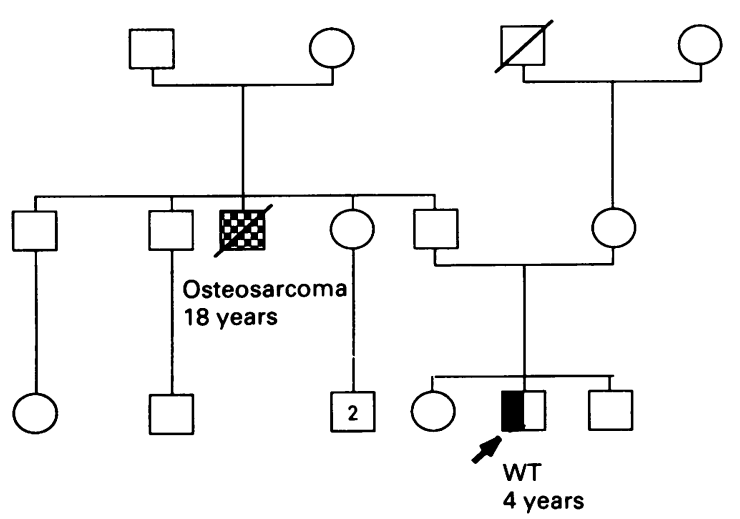

4

5
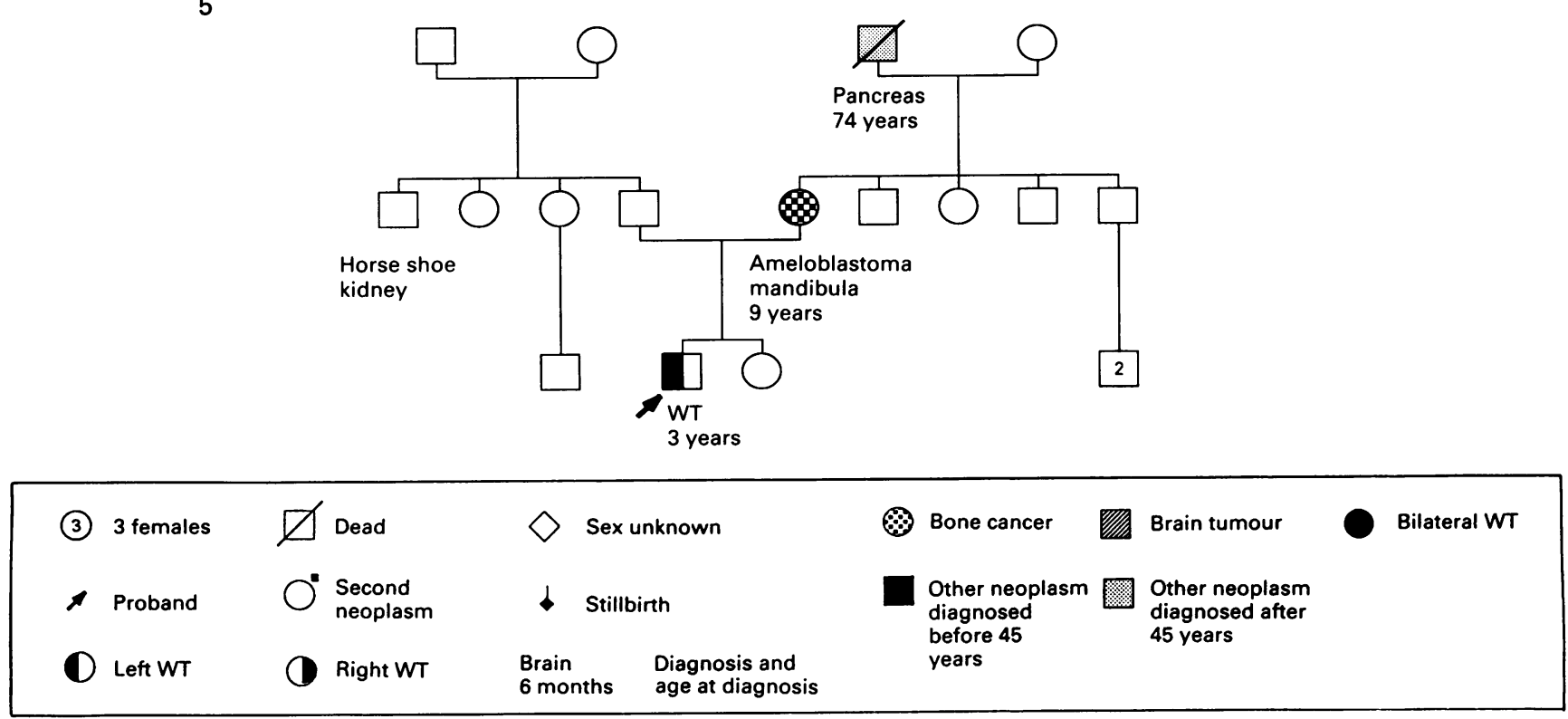

Figure 1 Pedigrees with relatives diagnosed with bone cancer before the age of 45 . 
The French Wilma' tumour study: no clear evidence for cancer prone families

433

6

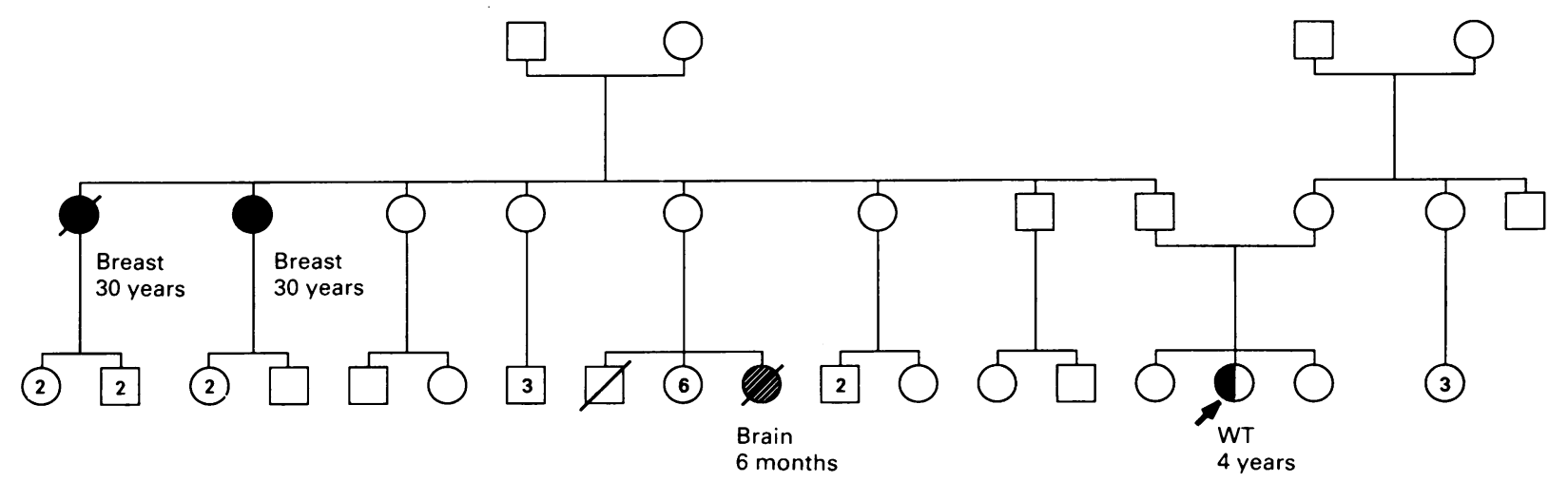

7

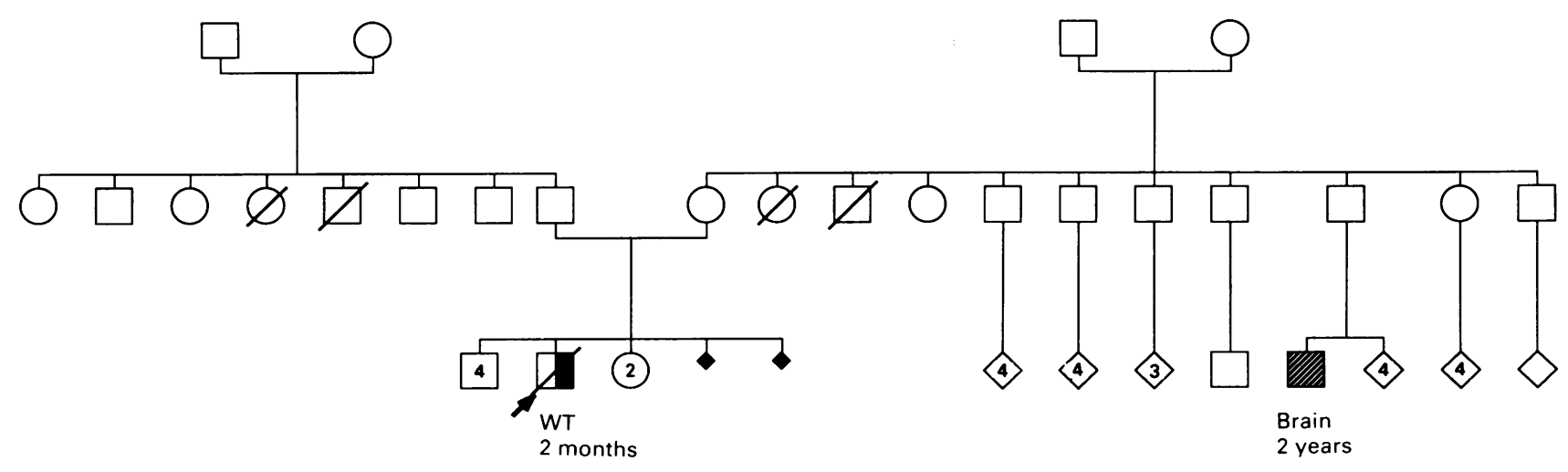

8

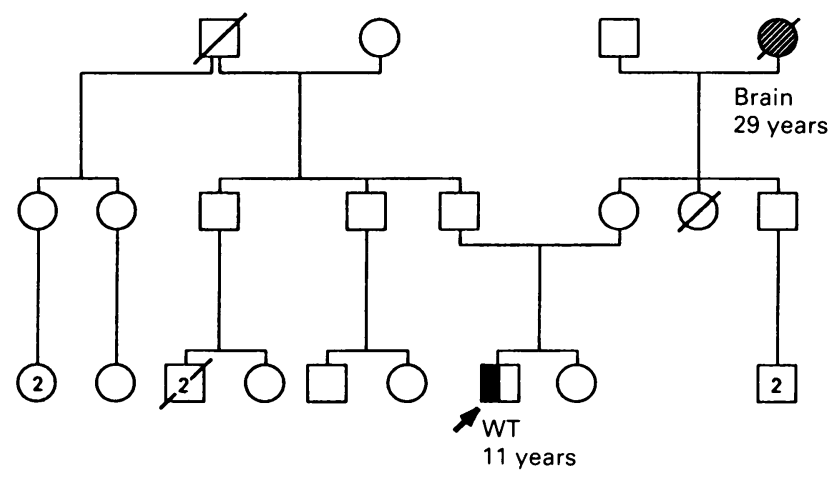

9

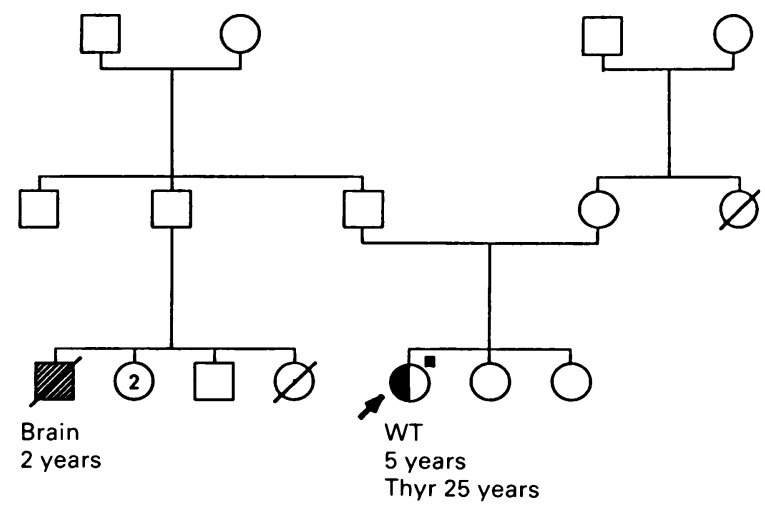

10

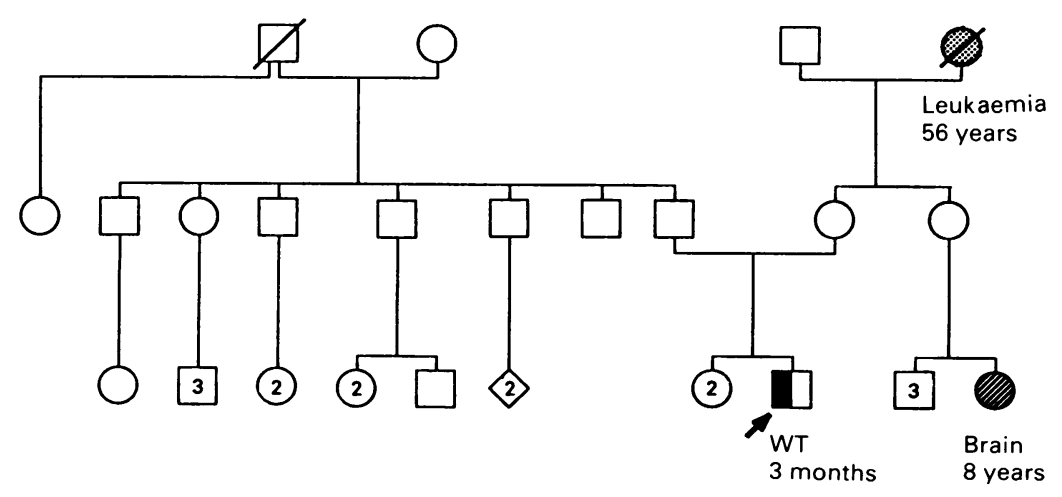

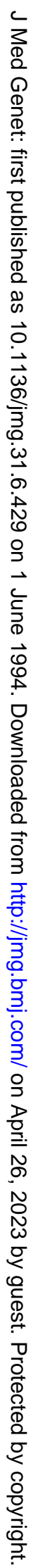

Figure 2 Pedigrees with relatives diagnosed with brain tumour before the age of 45 . 
diagnosis and especially of recent cancers which may be still unknown by family members. The observed number of cancers might thus be greater than it is. Second, since cancer incidence has been increasing with time, our recent population data may lead to an overestimation of the expected number of families with at least one relative diagnosed as having cancer before the age of 45 . This could explain the deficit of families when we deal with all types of cancer (39 observed versus 78 expected). We thus reduced the possibility of showing an excess.

Soft tissue sarcomas and breast cancers are the most common features of the LFS. Analysis of 501 families showed no excess when testing for these cancers. These results provide no evidence for WT being part of this cancer syndrome. However, the excess of bone and brain tumours could reflect a very small proportion of families in which a susceptibility gene segregates. Two families (families 2 and 6 ) could be the result of such a mechanism and it would be interesting to investigate them at a molecular level to confirm this hypothesis.

This work was supported by grants from the Association pour la Recherche sur le Cancer, the Ligue Nationale contre le Cancer, the Caisse Nationale d'Assurance Maladie des Travailleurs Salariés, and the Faculté de Médecine Paris-Ouest.

1 Breslow N, Olshan A, Beckwith JB, Green DM. Epidemiology of Wilms tumor. Med Pediatr Oncol 1993;21:17281 .

2 Knudson AG. Mutation and cancer: statistical study of retinoblastoma. Proc Natl Acad Sci USA 1971;68:820-3.

3 Knudson AG, Strong LC. Mutation and cancer: a mode for Wilms' tumor of the kidney. $\mathcal{f}$ Natl Cancer Inst 1972;48:313-24.

4 Riccardi VM, Sujanski E, Smith AC, Francke U. Chromosomal imbalance in the aniridia-Wilms' tumor association: $11 \mathrm{p}$ interstitial deletion. Pediatrics 1978;61:604-10.

5 Van Heyningen V, Hastie ND. Wilms' tumour: reconciling genetics and biology. Trends Genet 1992;8:16-21.

6 Grundy P, Koufos A, Morgan K, Li FP, Meadows AT, Cavenee WK. Familial predisposition to Wilms' tumor does not map to the short arm of chromosome 11. Nature 1988;336:374-6.

7 Huff V, Compton DM, Chao LY, Strong LC, Geiser CF, Saunders GF. Lack of linkage of familial Wilms' tumour to chromosomal band 11p13. Nature 1988;336:377-8.

8 Schwartz CE, Haber DA, Stanton VP, Strong LC, Skolnick MH, Housman DE. Familial predisposition to Wilms'
tumor does not segregate with the WT1 gene. Genomics tumor does not

9 Bond DJV. Bilateral Wilms' tumour. Age at diagnosis, associated congenital anomalies and possible pattern of associated congenital anomalies and

10 Moutou C, Chompret A, Hochez J, et al. Testing genomic imprinting in Wilms' tumor. Eur f Hum Genet 1993;1: 190-205.

11 Schroeder WT, Chao LY, Dao DD, et al. Nonrandom loss of maternal chromosome 11 alleles in Wilms' tumor. $A m \mathcal{J}$ Hum Genet 1987;40:413-20.

12 Williams JC, Brown KW, Mott AG, Maitland NJ. Maternal allele loss in Wilms' tumor. Lancet 1989;i:283-4

13 Pal N, Wadey RB, Buckle B, Yeomans E, Pritchard J, Cowell JK. Preferential loss of maternal alleles in sporadic Wilms' tumour. Oncogene 1990;5:1665-8

14 Moutou C, Junien C, Henry I, Bonaiti-Pellié C. BeckwithWiedemann syndrome: a demonstration of the mechanisms responsible for the excess of transmitting females. $\mathcal{F}$ Med Genet 1992;29:217-20.

15 Viljoen D, Ramesar R. Evidence for paternal imprinting in familial Beckwith-Wiedemann syndrome. $\mathcal{f}$ Med Genet 1992;29:221-5.

16 Brown KW, Williams JC, Maitland NJ, Mott MG. Genomic imprinting and the Beckwith-Wiedemann syndrome. Am ₹ Hum Genet 1990;46:1000-1.

17 Zhang Y, Tycko B. Monoallelic expression of the human H19 gene. Nature Genet 1992;1:40-4.

18 Zhang Y, Shields T, Crenshaw T, Hao YM Moulton T, Tycko B. Imprinting of human $\mathrm{H} 19$ : allele-specific $\mathrm{CpG}$ methylation, loss of the active allele in 'Wilms' tumor methylation, loss of the active allele in Wilms' tumor, and potential for somat

19 Bonaiti-Pellié C, Chompret A, Tournade MF, et al. Genetics and epidemiology of 'Wilms' tumor: the French

20 Li FP, Fraumeni JF. Prospective study of a family cancer syndrome. $\mathcal{F} A M A$ 1982;247:2692-4

21 Li FP, Fraumeni JF, Mulvihill JJ, et al. A cancer family syndrome in twenty-four kindreds. Cancer Res 1988;48:5358-62.

22 Birch JM, Hartley AL, Blair V, et al. Cancer in the families of children with soft tissue sarcoma. Cancer 1990;66:2239-48.

23 Hartley AL, Birch JM, Tricker K, et al. Wilms' tumor in the Li-Fraumeni cancer family syndrome. Cancer Genet Cytogenet 1993;67:133-5.

24 Hill C, Benhamou E, Doyon F, Flamant R. Statistiques de santé: évolution de la mortalité par cancer en France entre 1950 et 1985. Paris: Editions INSERM, 1989.

25 INSERM. Statistiques des causes médicales de décès. Paris Editions INSERM, 1990.

26 Benhamou E, Laplanche A, Wartelle M, et al. Statistiques de santé: incidence des cancers en France 1978-1982. Paris Editions INSERM, 1990

27 Monson RR. Analysis of relative survival and proportional mortality. Comp Biomed Res 1974;7:325-32.

28 Bonaïti-Pellie C, Briard-Guillemot ML. Excess of cance deaths in grandparents of patients with retinoblastoma. $f$ Med Genet 1980;17:95-101.

29 Bonaiti-Pellie C, Chompret A, Tournade MF, Zucker JM, Lemerle J. Etude génétique et épidémiologique française Cancer 1988;75:131-3. 